\title{
Comorbid painful physical symptoms and anxiety: Prevalence, work loss and help-seeking
}

\author{
Koen Demyttenaere ${ }^{\mathrm{a}, *}$, Anke Bonnewyn ${ }^{\mathrm{a}}$, Ronny Bruffaerts ${ }^{\mathrm{a}}$, Ron De Graaf ${ }^{\mathrm{b}}$, \\ Josep Maria Haro ${ }^{c}$, Jordi Alonso ${ }^{\mathrm{d}}$ \\ a Department of Psychiatry, University Hospital Gasthuisberg, Leuven, Belgium \\ ${ }^{\mathrm{b}}$ Netherlands Institute of Mental Health and Addiction (Trimbos), Da Costakade 45, PB 725, 3500 AS Utrecht Utrecht, The Netherlands \\ ${ }^{\mathrm{c}}$ Fundacao Sant Joan de Deu, Barcelona, Spain \\ ${ }^{\mathrm{d}}$ Health Services Research Unit, Institut Municipal d'Investigacio Medica (IMIM-IMAS), Barcelona, Spain
}

Received 16 July 2007; received in revised form 13 December 2007; accepted 13 December 2007

Available online 30 January 2008

\begin{abstract}
Background: There is evidence that painful physical symptoms (PPS) are increased in patients with anxiety disorder (AD). This survey reports the 12-month prevalence and sociodemographic characteristics of PPS in subjects with and without AD, taking into account somatic comorbidity. In addition, the impact of PPS on work loss days (WLDs) and help-seeking was examined.

Methods: In a cross-sectional, population-based study, a representative random sample of non-institutionalised adults from Belgium, France, Germany, Italy, The Netherlands and Spain $(N=21,425)$ was interviewed using the World Mental Health Composite Diagnostic Interview (CIDI 3.0 of the WHO). 8296 respondents provided data on the occurrence of PPS, from which 5489 respondents reported the number of work loss days.

Results: PPS were reported by $28 \%$ of respondents without AD and by $45 \%$ in those with AD. Female gender, higher age and lower educational level were predictive of PPS. No additive effect of AD and PPS was found on the WLD score, neither did the presence or not of a comorbid somatic disorder change the findings. Finally, respondents with both AD and PPS had numerically higher rates of help-seeking for emotional reasons ( $20.8 \%$ vs. $15.0 \%$ for respondents with AD but not PPS) and delayed their helpseeking for a numerically shorter period of time ( 289 vs. 413 days, respectively).

Limitations: The most important limitation of this study was its reliance on self-reported data about somatic disorders.

Conclusion: Approximately $45 \%$ of persons with anxiety disorder also reported the presence of PPS. No additive effect of AD and PPS was found on the WLD score, and the presence of PPS in AD does not delay help-seeking for emotional problems.
\end{abstract}

(C) 2008 Elsevier B.V. All rights reserved.

Keywords: Anxiety disorder; Painful physical symptoms; Work loss days; Help-seeking

* Corresponding author. University Psychiatric Center Kuleuven, campus Leuven, Herestraat 49, B-3000 Leuven, Belgium. Tel.: +32 1634 8701; fax: +3216348700 .

E-mail address: koen.demyttenaere@med.kuleuven.be (K. Demyttenaere).

\section{Introduction}

Although there is a considerable body of literature on the frequency of painful physical symptoms (PPS) in depressed patients, there are fewer data on the 
prevalence of PPS among individuals with anxiety disorders. However, the evidence suggests that PPS is not specific to depression but is also increased in anxiety, a finding seen both in population-based samples and in the clinic situation. The World Health Organization Collaborative Study of Psychological Disorders in Primary Care (Sartorius et al., 1993) found that International Classification of Diseases (ICD)-10 persistent somatoform pain disorder (current pain for most of the time over a six-month period in the prior year, and which bothered the patient a great deal) was found in as many patients with anxiety but without depression $(35.3 \%)$ as in those with depression without anxiety $(32.4 \%)$, both proportions higher than the $8.6 \%$ of patients with no disorder. In a recent US population survey of the comorbidity of physical pain and mental disorders, chronic spinal pain was found in $31.4 \%$ of respondents with an anxiety disorder (AD) and in 15.9\% of those with no mental disorder (Von Korff et al., 2005). A study carried out in individuals recruited from clinic and community sources in the US found higher rates of arthritis, migraine and back pain in respondents with an anxiety disorder than those without, the differences reaching statistical significance in the case of migraine for both male $(23.2 \%$ vs. $5.0 \%)$ and female (34.3\% vs. $12.1 \%$ ) respondents (Härter et al., 2003). The Nord-Trondelag Health study (HUNT) of the general population showed increased odds of finding migraine, fibromyalgia and musculo-skeletal symptoms in people with AD than in those without (Stordal et al., 2003).

Conversely, there are also reports of an increased incidence of anxiety disorders among people with chronic or persistent pain. In a US study of individuals with chronic tension headaches, $34.7 \%$ were diagnosed with $\mathrm{AD}$ compared with $2.2 \%$ of control subjects who did not suffer from headaches (Holroyd et al., 2000). Similarly, a longitudinal cohort study in New Zealand into headache found that at age 26 , the percentage of individuals having $\mathrm{AD}$ was increased in those with any of the headache types investigated $(10.1 \%$ to $13.9 \%)$ compared with those with no headache (6.2\%) (Waldie and Poulton, 2002). In a World Health Organization study carried out among people attending primary care centres in Asia, Africa, Europe and the Americas, 33.7\% of those with persistent pain met the ICD-10 definition of anxiety or depression compared with $10.7 \%$ of those without persistent pain (Gureje et al., 1998), although this report did not distinguish between anxiety or depression.

Studies which recorded the demographic characteristics of respondents with PPS have shown higher rates in female than male patients, although the differences are, in some cases, modest (Von Korff et al., 2005; Gureje et al., 1998; Haug et al., 2004). For headache/ migraine, however, the increased incidence of symptoms in female patients appears greater (Waldie and Poulton, 2002; Benseňor et al., 2003; Haug et al., 2004). The prevalence of PPS also increases with age, at least up to about 60 years (Von Korff et al., 2005; Benseňor et al., 2003), although this finding is not unexpected if lifetime prevalence is being assessed.

Some studies of anxiety disorders in patients with chronic symptoms of pain distinguish between generalised anxiety disorder (GAD), panic disorder and phobias. In general, the association between medical illness and anxiety is greater for those patients with GAD or panic disorder than for those with phobias (Härter et al., 2003). Two studies have found that GAD, panic disorder, post-traumatic stress disorder and other anxiety disorders except for agoraphobia are significantly more common in patients with chronic spinal pain (Von Korff et al., 2005) or arthritis (Stang et al., 2006) than in those without. More generally, there is a strong relationship between anxiety and the number of functional somatic symptoms (Haug et al., 2004), several of these involving pain. While Haug et al. recognise that certain symptoms are included in the diagnostic criteria for $\mathrm{AD}$, it is also possible that patients with anxiety might have a lower threshold for symptom reporting. Indeed, a study conducted in patients with anxiety disorders found that those with GAD or panic disorder were more sensitive to bodily sensations, such as rapid heart beat, sweating and breathing difficulty, than normal controls (HoehnSaric et al., 2004).

There is now increasing recognition of the part that comorbid mental disorders play in role impairment and disability in the workplace. The National Comorbidity Survey in the US found that comorbid mental-physical disorders resulted in more impairment than either mental or physical disorders alone (Kessler et al., 2003). The number of role impairment days in a 30-day period due to arthritis, asthma and ulcers was significantly increased in the presence of comorbid generalised anxiety disorder (by 3.9, 5.9 and 4.8 days, respectively). A study carried out in The Netherlands found that the presence of a mental disorder generally increased absence from work. For respondents with back trouble, rheumatism or migraine as well as $\mathrm{AD}$, the excess number of days in a 12-month period on which they were unable to work was $23.8,18.7$ and 16.3 , respectively, over respondents without AD (Buist-Bouwman et al., 2005).

This paper reports the results over an investigation into the relationship between anxiety disorder and PPS 
in 21,425 adults in the general population from the ESEMeD/MHEDEA project in six European countries. Specific objectives were to examine (a) the prevalence of painful physical symptoms in individuals with anxiety disorder and (b) the comparison between $\mathrm{AD}$ with PPS and AD without PPS for sociodemographic characteristics, work loss days and help-seeking behaviour.

\section{Methods}

\subsection{Sample}

Individuals were assessed in person at their homes using computer-assisted interview (CAPI) techniques. The target population was the non-institutionalised adult population (aged 18 years or older) of Belgium, France, Germany, Italy, The Netherlands and Spain (representing a total of 212,000,000 Europeans). A stratified, multi-stage, clustered area, probability sample design was used (for further description see Alonso et al., 2002, 2004).

Verbal informed consent was obtained, and the institutional review board of the organization that coordinated the survey in each country approved the procedures for obtaining informed consent and protecting human subjects. In total, 21,425 respondents provided data for the project between January 2001 and July 2003. The overall response rate in the six countries investigated was $61.2 \%$. Prevalence estimates were weighted to restore the distribution of the national population within each country as well as to adjust for the different proportions of respondents in each country.

\subsection{Instruments}

\subsubsection{Mental disorder status}

Data were assessed by means of the World Mental Health Composite International Diagnostic Interview (CIDI 3.0 of the WHO) (Kessler and Ustun, 2004), which was developed and adapted by the World Mental Health Survey Initiative (Kessler and Ustun, 2004; Kessler et al., 2004). Prevalence estimates of anxiety disorder were determined by whether respondents' symptomatology met the 12-month diagnostic criteria for this disorder (generalised anxiety disorder, specific phobia, social phobia, agoraphobia, post-traumatic stress disorder, or panic disorder). Since the presence of mood disorders is known to be correlated with a higher prevalence of PPS and since the aim of this paper was to investigate the relation between $\mathrm{AD}$ and PPS, patients with comorbid 12 month mood disorders were excluded from all analyses (Demyttenaere et al., 2006). Disorders were assessed using the criteria of the Diagnostic and Statistical Manual of Mental Disorders, Fourth Edition (DSM-IV) (American Psychiatric Association, 1994).

Methodological evidence collected in the WHO CIDI 3.0 Field Trials and later clinical calibration studies showed that all the disorders considered herein were assessed with acceptable reliability and validity (Kessler et al., 2004). The recent clinical reappraisal studies carried out in four countries (US, Italy, Spain and France, with total $N=468$ ) have provided evidence for a good concordance between CIDI 3.0 diagnoses and diagnoses based on blinded re-interviews, with area under the receiver operator characteristics curve ranging between $0.73-0.93$ for lifetime mood/anxiety disorders, and $0.83-0.88$ for 12 -month mood/anxiety disorders (Haro et al., 2006).

\subsubsection{Painful physical symptoms}

PPS were assessed through questions about the lifetime prevalence of or treatment for any frequent or severe headache, neck or back pain. In the present report, subjects were considered to have PPS when they gave an affirmative answer to at least one of these three questions presented in Box 1, indicating whether they still had these pain symptoms in the past 12 months. The PPS section was administered to 8796 respondents.

\subsubsection{Chronic somatic disorders}

Participants were also asked if they had ever had any of the following chronic somatic disorders: arthritis or rheumatism, seasonal allergies, a stroke, a heart attack, heart disease, high blood pressure, asthma, tuberculosis, other chronic lung diseases, malaria or another parasitic disease, diabetes or high blood sugar, an ulcer in their stomach or intestine, a thyroid disease, a neurological

\section{Box 1}

Selected questions about painful physical symptoms

Painful physical symptoms

(CC4B) Did you still have back or neck problems or receive any treatment for them at any time during the past 12 months? (CC4C) Did you still have frequent or severe headaches or receive any treatment for them at any time during the past 12 months? (CC4D) Did you still have (any other) chronic pain or receive any treatment for it during the past 12 months? 


\section{Box 2} The work loss index of the World Health
Organization

'Work loss days' - index

(Q1) Starting yesterday and going back 30 days, how many days out of the past 30 were you totally unable to work or carry out your normal activities because of problems with either your physical health, your mental health, or your use of alcohol or drugs? (Q2) How many days out of the past 30 were you able to work and carry out your normal activities but had to cut-down on what you did or not get as much done as usual because of problems with either your physical health, your mental health, or your use of alcohol or drugs?

(Q3) How many days out of the past 30 did you cut-back on the quality of your work or how carefully you worked because of problems with either your physical health, your mental health, or your use of alcohol or drugs?

problem, HIV, AIDS or cancer. When a participant did report at least one of these somatic disorders, he/she was considered 'with somatic disorder', otherwise he/she was considered 'without somatic disorder'.

\subsubsection{Work loss days}

The CIDI 3.0 of the WHO used in the ESEMeD survey also included a series of questions about decrease in work productivity, as assessed by means of the 'Work Loss Day' (WLD) of the WHO Disablement Assessment Scale version 2 (WHO-DAS-2). The timeframe of the WHO-DAS-2 is the 30 days prior to performing the assessment. The WLD questions are presented in Box 2. The responses were combined to create the WLD index: $\mathrm{WLD}$ index $=[\operatorname{sum}(1.0 * \mathrm{Q} 1)+(0.5 * \mathrm{Q} 2)+(0.5 * \mathrm{Q} 3)] / 30$ (Alonso et al., 2004). The WLD index is to be interpreted as the number of days per month that respondents have experienced a decrease in work productivity, e.g. a WLD index of 0.10 is interpreted as a $10 \%$ decrease in productivity per month $(10 \%$ of 30 days $=3$ days $)$. The WHO-DAS-2 was administered to selected subgroups in the two-step selection process. A first selection was based on their answers to questions 2 to 8 of the Short Form-12 (SF-12) in the screening section and was administered to $100 \%$ of the highly impaired and to $10 \%$ of the respondents with low impairment $(N=8796)$ (Fig. 1). Within this group, the WHO-DAS-2 was administered to all respondents with any mood or anxiety symptoms and to $25 \%$ of those respondents without any of these symptoms $(N=5489)$. These 5489 respondents were weighted in order to represent the original sample of 21,425 respondents.

\subsubsection{Use of services and help-seeking}

The use of services was assessed by asking respondents if, in the past 12 months, they ever saw any of the following types of professional for problems with emotions, nerves, mental health, or use of alcohol: psychiatrist, psychologist, general practitioner, or other health care professionals. If they sought professional help for their problems, the number of days they delayed their first professional contact was also assessed ("How long had you been thinking that you needed to see a professional before you started treatment?").

\subsection{Statistics}

We provide prevalence estimates of 12-month anxiety disorders and PPS by reporting weighted percentages (\%) and standard errors (SE). Analyses were stratified for the presence of somatic disorders since the association between anxiety disorders and PPS might be higher in respondents with a somatic disorder. WLD scores are also provided using mean scores and standard errors. Correlates of PPS are also provided using odds ratios (OR) and 95\% confidence intervals $(95 \% \mathrm{CI})$. They were adjusted for sociodemographic characteristics and the presence of anxiety disorder. Cuzick's Z-test

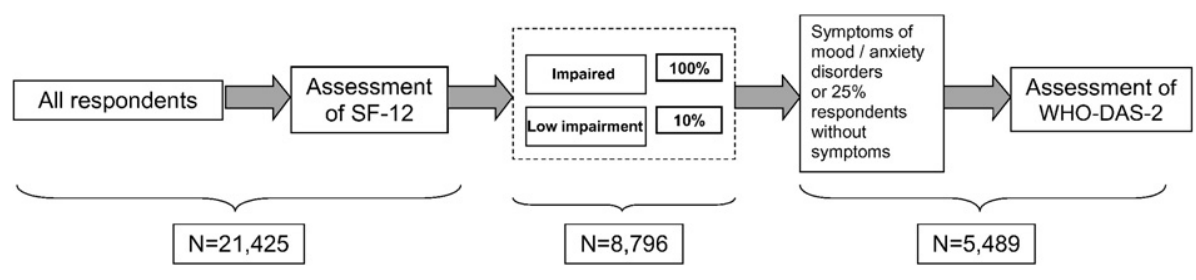

Fig. 1. Assessment of the WHO-DAS-2 in the ESEMeD project. 
Table 1

PPS and sociodemographic variables

\begin{tabular}{|c|c|c|c|c|}
\hline \multirow[t]{2}{*}{$\begin{array}{l}\text { Demographic } \\
\text { group }\end{array}$} & \multirow[t]{2}{*}{$\begin{array}{l}\text { Demographic } \\
\text { category }\end{array}$} & \multirow{2}{*}{$\begin{array}{l}\text { 12-month } \\
\text { prevalence } \\
\%\end{array}$} & \multirow{2}{*}{$\begin{array}{l}\text { 12-month } \\
\text { prevalence } \\
\text { if anxiety }=0 \\
\%(\mathrm{SE})\end{array}$} & \multirow{2}{*}{$\begin{array}{l}\text { 12-month } \\
\text { prevalence } \\
\text { if anxiety }=1 \\
\%(\mathrm{SE})\end{array}$} \\
\hline & & & & \\
\hline Sample & $\begin{array}{l}\text { All } \\
\text { respondents }\end{array}$ & 29.3 & $28.2(0.02)$ & $45.0(0.02)$ \\
\hline \multirow[t]{2}{*}{ Sex } & Male & 24.0 & $23.2(0.01)$ & $39.9(0.05)$ \\
\hline & Female & 34.4 & $33.1(0.01)$ & $47.2(0.03)$ \\
\hline \multirow[t]{5}{*}{ Age } & $18-24$ & 20.7 & $18.9(0.02)$ & $36.6(0.06)$ \\
\hline & $25-34$ & 25.9 & $25.1(0.01)$ & $37.9(0.05)$ \\
\hline & $35-49$ & 29.9 & $28.6(0.01)$ & $45.7(0.04)$ \\
\hline & $50-64$ & 33.7 & $32.1(0.02)$ & $54.0(0.05)$ \\
\hline & $>64$ & 31.8 & $31.3(0.02)$ & $47.7(0.09)$ \\
\hline \multirow[t]{4}{*}{ Education } & $0-4$ & 32.4 & $30.9(0.02)$ & $47.3(0.04)$ \\
\hline & $5-8$ & 32.9 & $32.2(0.02)$ & $44.9(0.05)$ \\
\hline & $9-12$ & 29.3 & $28.3(0.02)$ & $44.7(0.05)$ \\
\hline & $>12$ & 23.8 & $22.3(0.01)$ & $42.8(0.04)$ \\
\hline \multirow{2}{*}{$\begin{array}{l}\text { Living } \\
\text { conditions }\end{array}$} & Living alone & 29.2 & $28.2(0.02)$ & $43.7(0.06)$ \\
\hline & $\begin{array}{l}\text { Living with } \\
\text { someone }\end{array}$ & 29.4 & $28.2(0.01)$ & $45.3(0.03)$ \\
\hline \multirow[t]{2}{*}{ Employment } & Employed & 27.0 & $26.0(0.01)$ & $41.2(0.03)$ \\
\hline & Other & 31.9 & $30.6(0.01)$ & $49.5(0.04)$ \\
\hline
\end{tabular}

(Cuzick, 1985) was used to test linear effects of continuous variables (i.e. age and educational attainment) on estimates of PPS. The additive or synergistic impact of joint anxiety disorders and PPS on work loss days was assessed by Wald statistics. We tested the hypothesis of whether the presence of both an anxiety disorder and PPS resulted in a higher WLD score than the sum of these conditions separately. Statistical significance was set at the (two-sided) 0.05 level of significance. All statistical calculations were performed using STATA 8.0 statistical software (Stata Statistical Software, 2003).

\section{Results}

\subsection{2-month prevalence of $A D$ and of PPS}

The 12-month prevalence of AD (without mood disorder comorbidity) was $5.1 \%(\mathrm{SE}=0.00)$. The 12 month prevalence of PPS was $29.3 \%(\mathrm{SE}=0.01), 20.4 \%$ in respondents without a somatic disorder and $37.6 \%$ in respondents with a somatic disorder. Approximately one in two respondents $(51.7 \%)$ met the criteria for a somatic disorder. Arthritis and rheumatism were the most common somatic disorders $(20.6 \%)$, followed by high blood pressure (16.6\%), seasonal allergies (14.4\%), thyroid disease (5.7\%) and asthma (5.6\%).

One PPS was reported by $23.3 \%(\mathrm{SE}=0.01)$ of respondents, two PPS were reported by $5.3 \%(\mathrm{SE}=0.00)$ and three PPS were reported by $0.8 \%(\mathrm{SE}=0.00)$ of respondents. Back or neck pain was reported by $20.9 \%$ of all respondents; $12.5 \%$ of respondents without a somatic disorder and $28.7 \%$ of respondents with a somatic disorder. Frequent or severe headaches were reported by $9.6 \%$ of all respondents; $8.1 \%$ of respondents without a somatic disorder and $11.0 \%$ of respondents with a somatic disorder. Lastly, (any other) chronic pain was reported by $5.7 \%$ of all respondents; $2.9 \%$ of respondents without a somatic disorder and $8.2 \%$ of respondents with a somatic disorder.

\subsection{Sociodemographic variables and PPS (Table 1)}

Female respondents were more likely to have PPS than male respondents $[34.4 \%$ vs. $24.0 \%$; OR $=1.63$ (95\% CI: $1.48-1.80)$ ]. The rate of PPS increased with age (from $20.7 \%$ in the youngest to $31.8 \%$ in the oldest cohort, Cuzick's $Z$-test $p<0.01)$ and decreased with higher levels of education (from $32.4 \%$ in respondents

Table 2

Prevalence estimates of PPS in respondents with and without AD

\begin{tabular}{|c|c|c|c|c|c|c|c|}
\hline Demographic group & & Sample \% (SE) & No $\mathrm{AD} \%(\mathrm{SE})$ & $p$-values ${ }^{\mathrm{a}}$ & $\mathrm{AD} \%(\mathrm{SE})$ & $p$-values ${ }^{\mathrm{b}}$ & OR $(95 \% \mathrm{CI})^{\mathrm{c}}$ \\
\hline \multirow[t]{3}{*}{ Sample } & Overall & $29.3(0.01)$ & $27.7(0.03)$ & & $42.0(0.03)$ & & $2.17(1.81-2.59)$ \\
\hline & Male & $24.0(0.01)$ & $22.9(0.01)$ & $<0.01$ & $35.9(0.05)$ & 0.19 & $2.49(1.79-3.46)$ \\
\hline & Female & $34.4(0.01)$ & $32.5(0.01)$ & & $44.7(0.03)$ & & $2.06(1.67-2.54)$ \\
\hline \multirow[t]{3}{*}{ Persons without a somatic disorder } & Overall & $20.4(0.01)$ & $19.1(0.01)$ & & $39.7(0.04)$ & & $2.61(1.94-3.52)$ \\
\hline & Male & $15.5(0.01)$ & $15.1(0.01)$ & $<0.01$ & $20.9(0.05)$ & $<0.01$ & $2.25(1.27-3.96)$ \\
\hline & Female & $25.4(0.01)$ & $23.4(0.01)$ & & $49.6(0.05)$ & & $2.76(1.95-3.93)$ \\
\hline \multirow[t]{3}{*}{ Persons with a somatic disorder } & Overall & $37.6(0.01)$ & $36.0(0.01)$ & & $43.3(0.04)$ & & $1.71(1.37-2.14)$ \\
\hline & Male & $32.4(0.02)$ & $30.9(0.02)$ & $<0.01$ & $46.6(0.06)$ & 0.56 & $2.22(1.45-3.41)$ \\
\hline & Female & $42.0(0.02)$ & $40.6(0.05)$ & & $41.9(0.05)$ & & $1.55(1.19-2.02)$ \\
\hline
\end{tabular}

\footnotetext{
${ }^{\mathrm{a}} p$-values indicate gender differences in the prevalence of PPS.

${ }^{\mathrm{b}} p$-values indicate gender differences in the prevalence of PPS.

c Odds ratios indicate the likelihood of occurrence of PPS in respondents with AD compared to the likelihood of occurrence of PPS respondents without $\mathrm{AD}$ (reference category).
} 
with the lowest level to $23.8 \%$ in respondents with the highest level, Cuzick's $Z$-test $p<0.01)$. Living with someone (compared with living alone) and being unemployed (compared with being employed) also resulted in a slightly higher prevalence estimate of PPS (Table 1).

\subsection{Comorbidity between $A D$ and PPS (Table 2)}

Compared with the reference group that does not meet the criteria of $\mathrm{AD}$, the adjusted odds of reporting PPS is more than doubled in respondents with anxiety disorder $(\mathrm{OR}=2.17)$. This is the case for male and female respondents overall (ORs of 2.49 and 2.06, respectively), and for respondents without a somatic disorder (ORs of between 2.25 and 2.76), although the likelihood for respondents with a somatic disorder is slightly less than doubled overall $(\mathrm{OR}=1.71)$, but more than doubled for male respondents (2.22 vs. 1.55 for females). Females show higher prevalence estimates of PPS in the overall sample $(p=0.03)$ and in the subgroup of respondents without $\mathrm{AD}$ (with or without a somatic disorder, $p=0.00$ and $p=0.00$, respectively). In the subgroup of respondents with $\mathrm{AD}$ the gender difference is statistically significant only in respondents without a somatic disorder $(p=0.00)$, but is not statistically significant in respondents with a somatic disorder $(p=0.56)$ (Table 2).

\subsection{Work loss days in AD with or without PPS (Table 3)}

In the subjects without AD, WLDs increased from $5 \%$ in those without PPS to $12 \%$ in those with PPS, whereas in subjects with AD WLDs were similar in those without and with PPS $(22 \%$ and $20 \%$, respectively). This result - that there appeared to be no increase in WLDs in subjects with both AD and PPS was seen in the subgroups of subjects both with and without somatic disorders.

Among those subjects without a somatic disorder, those without either PPS or AD reported 1.2 WLDs (i.e. $4 \%$ of 30 work days in a month), respondents with PPS and without $\mathrm{AD}$ reported $2.7 \mathrm{WLDs}$, respondents with AD and without PPS reported 3.6 WLDs and those with both AD and PPS reported 3.0 WLDs. Subjects with a somatic disorder reported more WLDs in each case: those without either PPS or AD reported 1.8 WLDs, respondents with PPS and without AD reported 3.9 WLDs, respondents with AD and without PPS reported 8.7 WLDs and those with both AD and PPS reported 6.9 WLDs. There were no gender variations in WLD scores (all $p>0.05$ ).
Table 3

Work loss days score in respondents with and without AD and with and without PPS, with or without a somatic disorder

\begin{tabular}{|c|c|c|c|c|c|c|c|c|}
\hline \multirow[t]{3}{*}{ Level } & \multirow[t]{3}{*}{$\mathrm{AD}$} & \multirow[t]{3}{*}{ PPS } & \multicolumn{6}{|c|}{ Work loss days score } \\
\hline & & & \multicolumn{2}{|c|}{ Sample } & \multicolumn{2}{|c|}{$\begin{array}{l}\text { No somatic } \\
\text { disorder }\end{array}$} & \multicolumn{2}{|c|}{$\begin{array}{l}\text { Somatic } \\
\text { disorder }\end{array}$} \\
\hline & & & $\begin{array}{l}\text { Mean } \\
\text { WLD }\end{array}$ & (SE) & $\begin{array}{l}\text { Mean } \\
\text { WLD }\end{array}$ & (SE) & $\begin{array}{l}\text { Mean } \\
\text { WLD }\end{array}$ & (SE) \\
\hline 1 & - & - & 0.05 & $(0.01)$ & 0.04 & $(0.01)$ & 0.06 & $(0.01)$ \\
\hline 2 & - & + & 0.12 & $(0.01)$ & 0.09 & $(0.02)$ & 0.13 & $(0.02)$ \\
\hline 3 & + & - & 0.22 & $(0.05)$ & 0.12 & $(0.05)$ & 0.29 & $(0.06)$ \\
\hline 4 & + & + & $0.20^{\mathrm{a}}$ & $(0.03)$ & $0.10^{\mathrm{b}}$ & $(0.03)$ & $0.23^{\mathrm{c}}$ & $(0.04)$ \\
\hline
\end{tabular}

Test for a synergistic effect of AD and PPS.

${ }^{\mathrm{a}}[\mathrm{PPS}] \times[\mathrm{AD}]: \quad F(1,110)=7.15, p=0.0086$ (levels $2+3$ vs. 4); $[\mathrm{PPS}] \times[\mathrm{AD}]: F(1,110)=0.85, p=0.3595$ (level 3 vs. level 4).

b $[\mathrm{PPS}] \times[\mathrm{AD}]: \quad F(1,110)=2.90, p=0.0916$ (levels $2+3$ vs. 4); $[\mathrm{PPS}] \times[\mathrm{AD}]: F(1,110)=0.21, p=0.6484$ (level 3 vs. level 4$)$.

${ }^{c}[\mathrm{PPS}] \times[\mathrm{AD}]: \quad F(1,110)=6.62, p=0.0114$ (levels $2+3$ vs. 4); $[\mathrm{PPS}] \times[\mathrm{AD}]: F(1,110)=0.99, p=0.3220($ level 3 vs. level 4).

\subsection{Help-seeking in AD with or without PPS}

In general, numerically fewer respondents with $\mathrm{AD}$ but without PPS had been seeking help for emotional reasons than respondents with both $\mathrm{AD}$ and PPS, although the difference was not significant $(15.0 \%$ vs. 20.8\%; OR $=0.94$ [95\% CI: 0.65-1.35]). Within the group of subjects with both AD and PPS, the proportion of respondents seeking help for emotional reasons was similar among those without and with a somatic disorder ( $21.8 \%$ vs. $20.2 \%$; OR $=1.12$ [95\% CI: $0.63-1.96]$ ). The mean delay in seeking help was 412.7 days in subjects with AD but without PPS and 289.2 days in those with both AD and PPS $(p=0.58)$. The presence of a somatic disorder in subjects with AD and PPS affected the delay, so that it tended to be longer in those with a somatic disorder and shorter in those without (406.8 days vs. 110.0 days; $p=0.07$ ).

\section{Discussion}

\subsection{2-month prevalence of $A D$ and of PPS}

The prevalence of PPS in respondents without AD (28\%) and with $\mathrm{AD}(45 \%)$ is in agreement with published data (Sartorius et al., 1993; Von Korff et al., 2005; Härter et al., 2003; Stordal et al., 2003).

In the case of headache there is some evidence for an increase in incidence when moving from population-based to primary care samples with reported rates of $24.5 \%$ and $32.4 \%$ in two population-based studies (Waldie and Poulton, 2002; Haug et al., 2004) and $45.2 \%$ in a primary care sample (Gureje et al., 1998). Studies where migraine 
was identified reported rates of $7 \%$ in a population-based sample (Waldie and Poulton, 2002) and 7.5\% in a mixed sample (Härter et al., 2003), rising to $15.5 \%$ and $29.6 \%$ in subjects who also had AD (Stordal et al., 2003; Härter et al., 2003). Our finding that prevalence estimates of PPS in patients with $\mathrm{AD}$ are higher in the presence of somatic disorders is not unexpected since pain is a major component of several of these disorders (e.g. arthritis, rheumatism, diabetes, ulcer, cancer,...).

\subsection{Sociodemographic variables and PPS}

We found that higher age is a powerful independent predictor of PPS, confirming results from other epidemiological surveys (Currie and Wang, 2004; Von Korff et al., 2005). It is well-known that the prevalence of several somatic disorders, e.g. arthritis or rheumatism where patients present with pain, increases with age (Stang et al., 2006).

Female gender was also found to be a significant independent predictor of PPS. Kroenke and Spitzer (1998) not only found that that medically unexplained symptoms were more common in women, but also that the effect of gender on symptom reporting was independent of psychiatric morbidity. Haug et al. (2004) found that the prevalence of almost all somatic symptoms was significantly higher in women than men. In some studies, however, female gender was no longer a significant predictor of somatic symptom reporting when other sociodemographic variables were controlled for (Sayar et al., 2003). The higher prevalence of PPS and a modestly higher pain severity were also found in other studies (Ohayon and Schatzberg, 2003; Bair et al., 2004; Currie and Wang, 2004).

In addition, respondents with a higher educational level showed a decreased likelihood for PPS, confirming the generally proposed inverse relation between educational attainment and the frequency of arthritis (Stang et al., 2006), back pain (Dionne et al., 2001; Currie and Wang, 2004) or headaches (Helmert et al., 2001).

\subsection{Comorbidity between $A D$ and PPS}

The presence of anxiety disorder more than doubled the prevalence of PPS, which is in close agreement with the increase in risk observed by Von Korff et al. (2005) in chronic spinal pain $(\mathrm{OR}=2.3)$. This association could arise due to the stress of living with pain, but it is also known that the neurotransmitters implicated in panic and phobic disorders are implicated in pain modulation (Verma and Gallagher, 2002). There was an increased prevalence both in respondents with and without a so- matic disorder, although the increase in risk was higher for those without a somatic disorder. This suggests that $\mathrm{AD}$ amplifies painful symptoms to a greater extent when other medical conditions are not present.

A concept as "somatosensory amplification" from Barsky and colleagues (Barsky et al., 1990) might be helpful in understanding this link. Somatosensory amplification refers to the tendency of experiencing physical sensations as more intense and noxious. There is a hypervigilance towards the body, which means that bodily sensations are frequently appraised as pathological and symptomatic of disease rather than normalizing them. It may be possible that anxious persons have a higher level of somatosensory amplification and consequently tend to report more symptoms of pain in comparison to non-anxious persons.

Several authors have found a relationship between the presence of somatic symptoms or syndromes and the likelihood of anxiety disorder (Kroenke, 2003; Henningsen et al., 2003; Stordal et al., 2003; Stein, 2001).

\subsection{Work loss days in AD with or without PPS}

Respondents with PPS alone had 3.6 WLDs per month, and respondents with AD alone had 6.6 WLDs per months. Respondents with both $\mathrm{AD}$ and PPS, however, had 6.0 WLDs per month showing that the two conditions were not additive. This result is in contrast to previous findings on MDE (major depressive episode) in this population, where the effects of MDE and PPS were found to be additive (Demyttenaere et al., 2006). The finding that in MDE concurrent pain results in an additional effect on work loss whereas in anxiety disorders it does not, suggests a less intimate relation between depression and pain than between anxiety and depression. In fact, the exact relation between depression, anxiety and pain (or other somatic symptoms) is still not yet fully elucidated.

Our analysis supports existing data showing that there is more WLDs in subjects with $\mathrm{AD}$ and a somatic disorder compared to subjects with $\mathrm{AD}$ and without a somatic disorder (Buist-Bouwman et al., 2005; Kessler et al., 2001). However, we found no additive effect of $\mathrm{AD}$ and PPS in either subgroup, i.e. respondents with or without a somatic condition.

\subsection{Help-seeking in AD with or without PPS}

The current data show that respondents with $\mathrm{AD}$ and PPS have slightly higher rates (not reaching statistical significance) of help-seeking than those with $\mathrm{AD}$ alone. The comorbidity of anxiety and PPS has no influence on 
the duration of delay of seeking help for emotional problems. Again, this is in contrast with depression, where 'comorbid' PPS resulted in lower rates of help-seeking for emotional problems and in a delayed help-seeking (Demyttenaere et al., 2006). It suggests that the comorbidity between depression and pain or between anxiety and pain has different consequences for the help-seeking process.

\subsection{Limitations}

This study has a few notable limitations that might hamper interpretation of the results of this cross-sectional examination. Firstly, the assessment of PPS was limited in that respondents gave an affirmative answer on the PPS screening questions. We did not gather somatic information on precise diagnosis or duration of the symptoms. Secondly, the ascertainment of co-occurring somatic disorders was also dependent upon the selfreporting of respondents. Against the background that the World Mental Health Surveys were conducted in many population samples, and primarily aimed at mental health, it was not feasible to include a more comprehensive assessment of somatic disorders. Previous reports have suggested that self-report measures of somatic disorders may be more amenable to distortion than data from medical records (Ferraro and Farmer, 1999). Although the diagnosis of arthritis can only be given after a medical investigation, there is convincing evidence that self-report methods show moderate to high agreement with medical records data (National Centre for Health Statistics, 1994). For example, following earlier studies (e.g. Warren, 1976; Kehoe et al., 1994), recent studies focusing on arthritis report high sensitivity (up to $71 \%$ ) and specificity (up to $70 \%$ ) between self-reports and medical data (Bombard et al., 2005). In addition, we stratified our results for only those somatic disorders which were included in the CIDI 3.0. We could therefore not rule out PPS caused by somatic disorders other than those included in the questionnaire. A third limitation is that the threshold for pain was different for back or neck problems (still have), headaches (frequent or severe) and other pains (still have) which could influence the respective prevalence rates.

\subsection{Summary}

The current study clearly demonstrates that sociodemographic variables (gender, age, educational level) predicted the presence of PPS. In respondents with AD, a two-fold increase in the prevalence of PPS was found. No additive effect of AD and PPS was found on the WLD score. Finally, and in contrast with depressive disorders, PPS in anxiety disorders do not delay help-seeking for emotional reasons.

Further research is needed for a better understanding of the complex relationship between anxiety, depression and painful physical symptoms and whether a more lumping approach (searching for a common underlying dimension) or a more splitting approach (trying to further disentangle these symptom clusters) is warranted.

\section{Role of the funding source}

The EU funding and the GSK funding (see also Acknowledgements) did not interfere with the design, the analysis or the preparation of the manuscript.

\section{Conflict of interest}

The authors declare that they do not have a conflict of interest in submitting this manuscript.

\section{Acknowledgements}

The authors wish to thank Jo Bartlett for editorial assistance.

This project was funded by the European Commission (Contract QLG5-1999-01042); FIS (00/0028-02), SAF 2000-1800-CE, the Piedmont Region (Italy), other local agencies and by an unrestricted educational grant from GlaxoSmithKline. The ESEMeD study was also carried out in conjunction with the World Mental Health (WMH) Survey Initiative. We thank the WMH staff for assistance with instrumentation, fieldwork, and data analysis. These activities were supported by the John D. and Catherine T. MacArthur Foundation, the Pfizer Foundation, the US Public Health Service (1R13MH066849, R01MH069864, and R01DA01-6558), Eli Lilly and Company, GlaxoSmithKline, Ortho-McNeil Pharmaceuticals and the Pan American Health Organization.

\section{References}

Alonso, J., Ferrer, M., Romera, B., et al., 2002. The European Study of the Epidemiology of Mental Disorders (ESEMeD/MHEDEA 2000) Project: rationale and methods. Int. J. Methods Psychiatr. Res. 11, 55-67.

Alonso, J., Angermeyer, M., Bernert, S., et al., 2004. Use of mental health services in Europe: results from the European Study on Epidemiology of Mental Disorders (ESEMeD) project. Acta Psychiatr. Scand. 109 (suppl 420), 47-54.

American Psychiatric Association, 1994. Diagnostic and Statistical Manual of Mental Disorders, Fourth ed. American Psychiatric Association, Washington DC.

Bair, M.J., Robinson, R.L., Eckert, G.J., Stang, P.E., Croghan, R.W., Kroenke, K., 2004. Impact of pain on depression treatment response in primary care. Psychosom. Med. 66, 17-22. 
Barsky, A.J., Wyshak, G., Klerman, G.L., 1990. The somatosensory amplification scale and its relationship to hypochondriasis. J. Psychiatr. Res. 24, 323-334.

Benseňor, I.M., Tófoli, L.F., Andrade, L., 2003. Headache complaints associated with psychiatric comorbidity in a population-based sample. Braz. J. Med. Biol. Res. 36, 1425-1432.

Bombard, J.M., Powell, K.E., Martin, L.M., Helmick, C.G., Wilson, W.H., 2005. Validity and reliability of self-reported arthritis. Am. J. Prev. Med. 28, 251-258.

Buist-Bouwman, M.A., de Graaf, R., Volleberg, W.A.M., Ormel, J., 2005. Comorbidity of physical and mental disorders and the effect on work-loss days. Acta Psychiatr. Scand. 111, 436-443.

Currie, S.R., Wang, J., 2004. Chronic back pain and major depression in the general Canadian population. Pain 107, 54-60.

Cuzick, J., 1985. A Wilcoxon type test for trend. Stat. Med. 4, 87-90.

Demyttenaere, K., Bonnewyn, A., Bruffaerts, R., Brugha, T., De Graaf, R., Alonso, J., 2006. Comorbid painful physical symptoms and depression: prevalence, work loss, and help seeking. J. Affect. Dis. 92, 185-193.

Dionne, C.E., Von Korff, M., Koepsell, T.D., Deyo, R.A., Barlow, W.E., Checkoway, H., 2001. Formal education and back pain: a review. J. Epidemiol. Community Health 55, 455-468.

Ferraro, K.F., Farmer, M.M., 1999. Utility of health data from social surveys: is there a gold standard for measuring morbidity? Am. Sociol. Rev. 64, 303-315.

Gureje, O., Von Korff, M., Simon, G.E., Gater, R., 1998. Persistent pain and well-being. A World Health Organization study in primary care. JAMA $8,147-151$.

Haro, J.M., Arbabzadeh-Bouchez, S., Brugha, T.S., de Girolamo, G., Guyer, M.E., Jin, R. et al., 2006. Concordance of the Composite International Diagnostic Interview Version 3.0 (CIDI 3.0) with standardized clinical assessments in the WHO World Mental Health Surveys. Int J Methods in Psychiatr Res 15, 167-180.

Härter, M.C., Conway, K.P., Merikangas, K.R., 2003. Associations between anxiety disorders and physical illness. Eur. Arch. Psychiatry Clin. Neurosci. 253, 313-320.

Haug, T.T., Mykletun, A., Dahl, A.A., 2004. The association between anxiety, depression, and somatic symptoms in a large population: the HUNT-II study. Psychosom. Med. 66, 845-851.

Helmert, U., Merzenich, H., Bammann, K., 2001. Correlation between educational status, chronic diseases and cardiovascular risk factors in young adults 18-29 years of age: results of a 1998 comprehensive German health survey. Soz. Praventivmed. 46, 320-328.

Henningsen, P., Zimmerman, T., Sattel, H., 2003. Medically unexplained physical symptoms, anxiety, and depression: a metaanalytic review. Psychosom. Med. 65, 528-533.

Hoehn-Saric, R., McLeod, D.R., Funderburk, F., Kowalski, P., 2004. Somatic symptoms and physiologic responses in generalized anxiety disorder and panic disorder. Arch. Gen. Psychiatry 61, 913-921.

Holroyd, K.A., Stensland, M., Lipchik, G.L., Hill, K.R., O’Donnell, F.S., Cordingley, G., 2000. Psychosocial correlates and impact of chronic tension-type headaches. Headache 40, 3-16.

Kehoe, R., Wu, S., Leske, M.C., et al., 1994. Comparing self-reported and physician-reported medical history. Am. J. Epidemiol. 139, 813-818.

Kessler, R.C., Ustun, T.B., 2004. The World Mental Health (WMH) survey initiative version of the World Health Organization (WHO)
Composite International Diagnostic Interview (CIDI). Int. J. Methods Psychiatr. Res. 13, 93-121.

Kessler, R.C., Greenberg, P.E., Mickelson, K.D., Meneades, L.M., Wang, P.S., 2001. The effects of chronic medical conditions on work loss and work cutback. J. Occup. Environ. Med. 43, 218-225.

Kessler, R.C., Ormel, J., Demler, O., 2003. Comorbid mental disorders account for the role impairment of commonly occurring chronic physical disorders: results from the National Comorbidity Survey. J. Occup. Environ. Med. 45, 1257-1266.

Kessler, R.C., Abelson, J., Demler, O., et al., 2004. Clinical calibration of DSM-IV diagnoses I the World Mental Health (WMH) version of the World Health Organization (WHO) Composite International Diagnostic Interview (CIDI). Int. J. Methods Psychiatr. Res. 13, $122-139$.

Kroenke, K., 2003. Patients presenting with somatic complaints: epidemiology, psychiatric co-morbidity and management. Int. J. Methods Psychiatr. Res. 12, 34-43.

Kroenke, K., Spitzer, R.L., 1998. Gender differences in the reporting of physical and somatoform symptoms. Psychosom. Med. 60, 150-155.

Ohayon, M.M., Schatzberg, A.F., 2003. Using chronic pain to predict depressive morbidity in the general population. Arch. Gen. Psychiatry 60, 39-47.

Sartorius, N., Ustun, T.B., Costa e Silva, J.A., Goldberg, D., Lecrubier, Y., Ormel, J., Von Korff, M., Wittchen, H.U., 1993. An international study of psychological problems in primary care: preliminary report from the World Health Organization collaborative project on psychological problems in general health care. Arch. Gen. Psychiatry 50, 819-824.

Sayar, K., Kirmayer, L.J., Taillefer, S.S., 2003. Predictors of somatic symptoms in depressive disorder. Gen. Hosp. Psych. 25, 108-114.

Stang, P.E., Brandenburg, N.A., Lane, M.C., Merikangas, K.R., Von Korff, M.R., Kessler, R.C., 2006. Mental and physical comorbid conditions and days in role among persons with arthritis. Psychosom. Med. 68, 152-158.

Stata Statistical Software, 2003. Statacorp. College Station, Texas.

Stein, D.J., 2001. Comorbidity in generalized anxiety disorder: impact and implications. J. Clin. Psychiatry 62 (suppl 11), 29-34.

Stordal, E., Bjelland, I., Dahl, A.A., Mykletun, A., 2003. Anxiety and depression in individuals with somatic health problems. The NordTrøndelag Health Study (HUNT). Scand. J. Prim. Health Care 21, 136-141.

Verma, S., Gallagher, R.M., 2002. The psychopharmacologic treatment of depression and anxiety in the context of chronic pain. Curr. Pain Headache Rep. 6, 30-39.

Von Korff, M., Crane, P., Lane, M., Miglioretti, D.L., Simon, G., Saunders, K., Stang, P., Brandenburg, N., Kessler, R., 2005. Chronic spinal pain and physical-mental comorbidity in the United States: results from the national comorbidity survey replication. Pain 113, 331-339.

Waldie, K.E., Poulton, R., 2002. Physical and psychological correlates of primary headache in young adulthood: a 26 year longitudinal study. J. Neurol. Neurosurg. Psychiatry 72, 86-92.

Warren, M.D., 1976. Interview surveys of handicapped people: the accuracy of statements about the underlying medical conditions. Rheumatol. Rehabil. 15, 295-302. 